\title{
Introduction to the Hindu Kush Himalaya Assessment
}

\section{Coordinating Lead Author}

Eklabya Sharma, International Centre for Integrated Mountain Development (ICIMOD), Kathmandu, Nepal, e-mail: eklabya.sharma@icimod.org (corresponding author)

\section{Lead Authors}

David Molden, International Centre for Integrated Mountain Development (ICIMOD), Kathmandu, Nepal, e-mail: david.molden@icimod.org

Atiq Rahman, Bangladesh Centre for Advanced Studies, Dhaka, Bangladesh,

e-mail: atiq.rahman@bcas.net

Yuba Raj Khatiwada, Ministry of Finance, Govt. of Nepal, Kathmandu, Nepal, e-mail: dryubaraj@gmail.com

Linxiu Zhang, International Ecosystem Management Partnership, United Nations Environment Programme and Center for Chinese Agricultural Policy, Chinese Academy of Sciences, Beijing, China,

e-mail: linxiu.zhang@un.org

Surendra Pratap Singh, Central Himalayan Environment Association, Nainital, India,

e-mail: surps@yahoo.com

Tandong Yao, Institute of Tibetan Plateau Research, Chinese Academy of Sciences, Beijing, China, e-mail: tdyao@itpcas.ac.cn

Philippus Wester, International Centre for Integrated Mountain Development (ICIMOD), Kathmandu, Nepal, e-mail: philippus.wester@icimod.org

Note: All authors are HIMAP Steering Committee Members, except Philippus Wester, who is HIMAP Coordinator

\section{Corresponding Author}

Eklabya Sharma, International Centre for Integrated Mountain Development (ICIMOD), Kathmandu, Nepal, e-mail: eklabya.sharma@icimod.org 


\section{Contents}

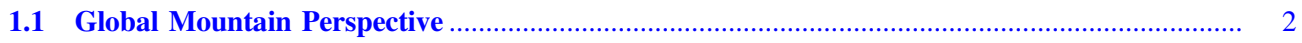

1.2 The Hindu Kush Himalaya-A Global Asset …............................................................ 3

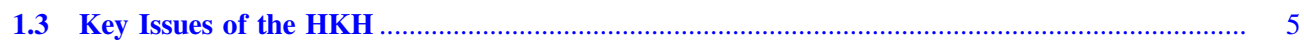

1.4 Overall Objective, Rationale and Key Questions …........................................................ 5

1.4.1 Overall Objective.................................................................................................... 5

1.4.2 Rationale for the Assessment .............................................................................. 5

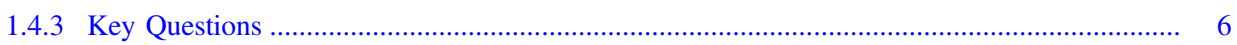

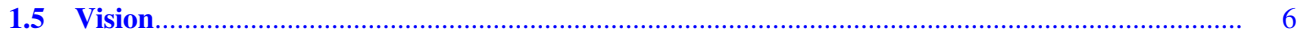

1.6 HKH Priorities Contributing to the Sustainable Development Goals..................................... 7

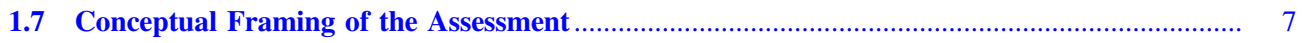

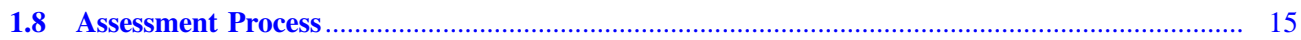

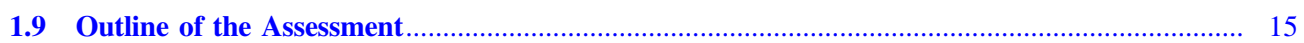

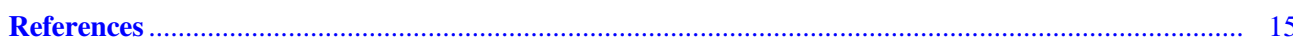

\subsection{Global Mountain Perspective}

Mountains are large landforms raised above the surface of the earth emerging into peaks and ranges. Mountains occupy $22 \%$ of the world's land surface area and are home to about $13 \%$ of the world's population (FAO 2015). While about 915 million people live in mountainous region, less than 150 million people live above $2,500 \mathrm{~m}$ above sea level (masl), and only 20-30 million people live above 3,000 masl.

About half of all humankind directly depends on mountain resources, primarily water. Mountains support $25 \%$ of world's terrestrial biodiversity and include nearly half of the world's biodiversity 'hotspots'. Of the 20 plant species that supply $80 \%$ of the world's food, six of those (apples, barley, maize, potatoes, sorghum and tomatoes) originated in mountains (Fleury 1999). In humid parts of the world, mountains provide $30-60 \%$ of the fresh water downstream; and in semi-arid and arid environments, they provide 70-95\% (Kapos et al. 2000; WCMC-UNEP 2002). Mountains provide goods and services of global significance in the form of water, hydroelectricity, timber, biodiversity and niche products, mineral resources, recreation, and flood management (Schild and Sharma 2011; Molden and Sharma 2013). Mountains are more diverse region rich in ethnicity and languages. In general, poverty is higher in mountain regions and people are often at higher risk than people elsewhere. According to a recent FAO analysis, $39 \%$ of mountain populations (urban and rural combined) in developing countries were considered vulnerable to food insecurity in 2012 , an increase of $30 \%$ compared to 12 years prior (FAO 2015).
Mountain geological formations are fragile and ecosystems are degrading fast because of both natural and anthropogenic drivers of change. Mountains are also places of cultural meaning and refuge. Many mountain inhabitants have settled there to escape religious or political persecution or wars in lowlands. Mountains are also often focal areas of armed conflict. Mountain areas have ecological, aesthetic, and socioeconomic significance, not only for people living there, but for those living beyond-especially those in the lowlands who benefit from the ecological services mountains provide. Thus, mountains, in one perspective, stand as some of the planet's last natural 'islands' in a sea of increasingly anthropogenic influenced lowlands, providing a number of significant ecological functions extending beyond mountain regions (Hamilton 2002).

Mountains also represent unique areas for detecting climate change and assessing climate change impacts (Nogues-Bravo et al. 2008; Dyuergerov and Meier 2005). As climate changes rapidly through elevation over relatively short horizontal distances, so do hydrology, vegetation, ecological conditions, and socio-economic settings (Whiteman 2000; Xu and Melick 2006). This rapid change over distance, in turn, also influences cultural values and societies. In this way, it is important to recognise the complexities of environment-society interactions culture and environment are mutually reciprocating systems.

The increasing awareness of climate change impacts on mountains, mountain ecosystems, and mountain communities have started drawing attention to mountains during international debates such as the United Nations Conference on Environment and Development in Rio de Janeiro in 1992, 


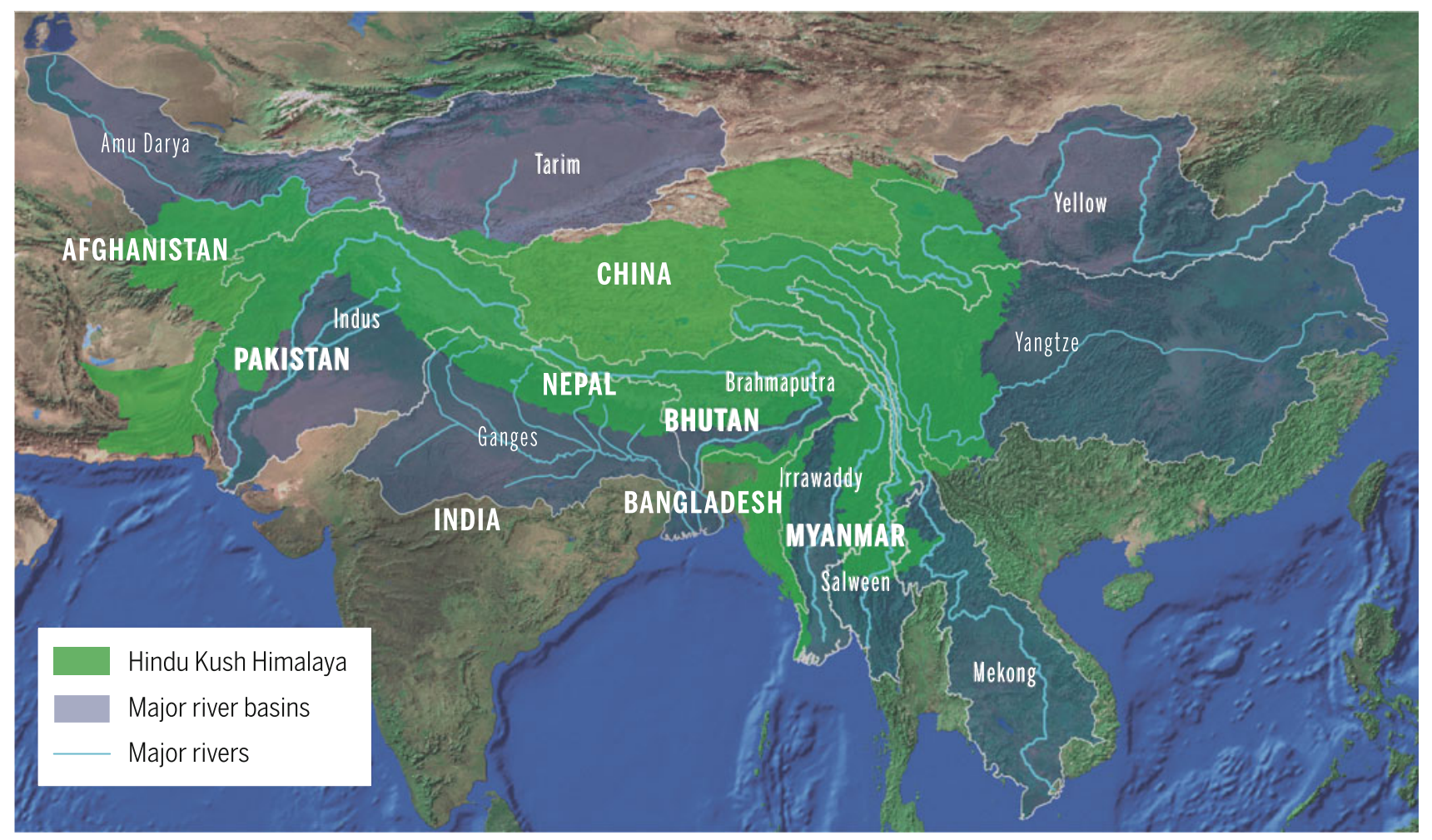

Fig. 1.1 The Hindu Kush Himalayan region and 10 major river basins

the Sendai Framework for Disaster Risk Reduction 2015, the Paris Agreement 2015 of the United Nations Framework Convention on Climate Change, and the Sustainable Development Goals (SDGs) and Targets 2030. There should be more pursuits for mountain perspectives to form an integral part in any discussions about future plans for sustainable development in the context of climate change. That means not just highlighting the vulnerabilities and fragilities inherent to mountain locations, but also emphasizing the resilience and strength that mountain people and communities bring when seeking to deal with these challenges.

\subsection{The Hindu Kush Himalaya_A Global Asset}

A critically important geo-ecological asset, the Hindu Kush Himalaya (HKH) is the origin of 10 major river basins and encompasses over 4.2 million $\mathrm{km}^{2}$ area (Bajracharya and Shrestha 2011; Bajracharya et al. 2015) (Fig. 1.1). This HKH area and Tien Shan mountains together form the largest area of permanent ice cover outside of the North and South Poles (hence, the occasional reference to the HKH as the "Third Pole") and is home to four global biodiversity hotspots, 330 important bird areas (Chettri et al. 2008), and hundreds of mountain peaks over $6,000 \mathrm{~m}$. The region provides ecosystem services (e.g., water, food, energy) that directly sustain the livelihoods of 240 million people in the mountain and hills of the HKH. Nearly 1.9 billion people living in the 10 river basins also benefit directly and indirectly from its resources (see Box 1.1), while more than 3 billion people enjoy the food produced in its river basins. The region is also home to some of the most diverse cultures, languages, religions, and traditional knowledge systems in the world.

\section{Box 1.1 Population of the Hindu Kush Himalaya and the ten major rivers basins originating in the Hindu Kush Himalaya}

Box Authors: Golam Rasul, Abid Hussain and Sudip Pradhan, ICIMOD

Based on the latest available government data sources and projections, in 2017 the population of the mountain and hills of the Hindu Kush Himalaya is around 240 million people (see Table 1.1). The total population in the ten major river basins with their headwaters in the $\mathrm{HKH}$ is around 1.9 billion, including the 240 million in the mountain and hills of the HKH (see Table 1.2).

The ethnic diversity and cultural wealth of the HKH extend from the Hindu Kush valleys in Afghanistan to the diverse hill 
Table 1.1 Population in the mountain and hills of the HKH

\begin{tabular}{|c|c|c|c|c|}
\hline Countries & Areas included in the $\mathrm{HKH}$ region & $\begin{array}{l}\text { Population of HKH } \\
\text { in million (Year of } \\
\text { data sources) }\end{array}$ & $\begin{array}{l}{ }^{\mathrm{a}} \text { Population in } 2017 \\
\text { (million) }\end{array}$ & $\begin{array}{l}\text { a Population in } 2030 \\
\text { (million) }\end{array}$ \\
\hline Afghanistan & $\begin{array}{l}\text { All provinces except the provinces of Kandahar, } \\
\text { Helmand, Nimroz, Farah, and Herat }\end{array}$ & $\begin{array}{l}\mathbf{2 2 . 8 5} \\
(2016-17)\end{array}$ & $22.85^{\mathrm{c}}$ & 29.91 \\
\hline Bangladesh & Chittagong hills & $\begin{array}{l}\mathbf{1 . 6 0} \\
(2011)\end{array}$ & 1.78 & 2.27 \\
\hline Bhutan & Entire territory & $\begin{array}{l}\mathbf{0 . 7 8}^{\mathrm{b}} \\
(2017)\end{array}$ & $0.78^{\mathrm{c}}$ & 0.96 \\
\hline China & $\begin{array}{l}\text { Parts of the provinces of Yunnan (Diqing, Nujiang } \\
\text { and Dali prefectures), Sichuan (Ganzi, Aba and } \\
\text { Liangshan prefectures), and Gansu (Gannan, } \\
\text { Wuwei and Zhangye prefectures); Xinjiang } \\
\text { autonomous region (Kashigar, Kezilesu, Hetian } \\
\text { and Altai prefectures); Tibet (entire territory), and } \\
\text { Qinghai province (entire territory) }\end{array}$ & $\begin{array}{l}32.51 \\
(2015)\end{array}$ & 33.29 & 38.86 \\
\hline India & $\begin{array}{l}\text { Entire territory of } 11 \text { mountain states (Assam, } \\
\text { Uttarakhand, Himachal Pradesh, Manipur, Jammu } \\
\text { and Kashmir (Indian administered area), } \\
\text { Meghalaya, Mizoram, Nagaland, Sikkim, Tripura, } \\
\text { Arunachal Pradesh), and Darjeeling and } \\
\text { Kalimpong districts of West Bengal state }\end{array}$ & $\begin{array}{l}76.98 \\
(2011)\end{array}$ & 86.27 & 110.44 \\
\hline Myanmar & Chin, Shan, Rakhine and Kachin states & $\begin{array}{l}\mathbf{1 1 . 1 8} \\
(2014)\end{array}$ & 11.70 & 14.24 \\
\hline Nepal & Entire territory & $\begin{array}{l}\mathbf{2 6 . 4 9} \\
(2011)\end{array}$ & 28.75 & 34.31 \\
\hline Pakistan & $\begin{array}{l}\text { Khyber Pakhtunkhwa province, } 24 \text { districts (out of } \\
\text { 32) of Balochistan province (excluded districts are } \\
\text { Kachhi, Gwadar, Jafarabad, Jhal Magsi, Lasbela } \\
\text { and Sohbatpur), Azad Jammu and Kashmir (AJK), } \\
\text { Gilgit-Baltistan and Federally administered Tribal } \\
\text { Areas (FATA) }\end{array}$ & $\begin{array}{l}\mathbf{5 1 . 4 7}^{\mathrm{d}} \\
(2017)\end{array}$ & $51.47^{\mathrm{c}}$ & 72.64 \\
\hline Total & & 223.86 & 236.90 & 303.63 \\
\hline
\end{tabular}

\section{Notes}

${ }^{a}$ Exponential projections of populations. The periods of growth rate estimation for HKH areas were 2009-2017 (Afghanistan), 2001-2011 (Bangladesh), 2010-2017 (Bhutan), 2011-2015 (China), 2001-2011 (India), 1983-2014 (Myanmar), 2001-2011 (Nepal), and 1998-2017 (Pakistan). These growth rates are used to project populations for 2017 and 2030

${ }^{\mathrm{b}}$ Projected population for 2017 procured from Statistical Year Book of Bhutan, 2016

${ }^{c}$ Population statistics for 2017 are directly collected from official sources of respective countries (Statistical Year Book of Bhutan 2016; Population Census of Pakistan 2017; Statistical Year Book of Afghanistan 2016-17)

${ }^{\mathrm{d}}$ Projected population of Azad Jammu and Kashmir and Gilgit-Baltistan for 2017 was added to the population of HKH areas procured from Population Census of Pakistan 2017

Sources (1) Data for latest population statistics are collected from Statistical Year Book of Afghanistan 2016-17; Population and Housing Census (Bangladesh) 2011; Statistical Year Book of Bhutan 2016; Year Books of China, Yunnan Province, Sichuan Province, Gansu Province, Xinjiang Autonomous Region (China) 2016; Population Census (India) 2011; Population and Housing Census of Myanmar 2014 (The Union Report, Volume 2); National Population and Housing Census of Nepal (national report) 2011; Population Census 2017; Govt. of AJK 2014; Govt. of Gilgit-Baltistan 2013

(2) Data for Base Year population (used for growth rate estimation) collected from Statistical Year Book of Afghanistan 2008-09; Population and Housing Census (Bangladesh) 2001; Statistical Year Book of Bhutan, 2016; Year Books of China, Yunnan Province, Sichuan Province, Gansu Province, Xinjiang Autonomous Region (China) 2012; Population Census (India) 2001; Population and Housing Census of Myanmar 2014 (The Union Report, Volume 2); National Population and Housing Census of Nepal (national report) 2011; Population Census (Pakistan) 1998 Assumptions for Projections In- and out-migration rates, fertility rate and mortality rate will remain stable

and mountain systems of Myanmar. Between these areas, we find the arid and semi-arid regions of the Pamir and Karakoram mountains; the high Himalaya of India, Nepal, and Pakistan; the un-spoilt beauty of Bhutan; the Tibetan Plateau of China; and the three parallel rivers of the Salween, Mekong and Yangtze in the far eastern region located in Yunnan Province of China. The HKH features great heterogeneity from north to south and east to west in relation to precipitation, vegetation, and human livelihoods. This variability defy making easy generalizations about the region. 
Table 1.2 Area and population of the ten major river basins originating in the $\mathrm{HKH}$

\begin{tabular}{l|c|c|c}
\hline River basins & $\begin{array}{l}{ }^{\mathrm{a}} \text { Area } \\
\left(\mathrm{km}^{2}\right)\end{array}$ & $\begin{array}{l}{ }^{\mathrm{b}} \text { Population in } \\
\text { 2010 (million) }\end{array}$ & $\begin{array}{l}{ }^{\mathrm{b}} \text { Population in } \\
\text { 2015 (million) }\end{array}$ \\
\hline Amu Darya & 645,870 & 27.19 & 30.18 \\
\hline Brahmaputra & 528,083 & 64.63 & 68.07 \\
\hline Ganges & $1,001,090$ & 539.43 & 580.09 \\
\hline Indus & $1,116,350$ & 244.31 & 268.42 \\
\hline Irrawaddy & 426,393 & 40.18 & 42.87 \\
\hline Mekong & 841,337 & 74.58 & 77.31 \\
\hline Salween & 363,898 & 18.19 & 17.88 \\
\hline Tarim & 929,254 & 10.65 & 11.37 \\
\hline Yangtze & $2,066,050$ & 600.92 & 604.94 \\
\hline Yellow & $1,073,440$ & 192.86 & 198.02 \\
River & & & $1,899.14$ \\
\hline Total & $8,991,765$ & $1,812.95$ & \\
\hline
\end{tabular}

Notes

${ }^{a}$ The area of individual basins have been calculated from basin boundary shapefile in Albers equal-area conic map projection developed by ICIMOD

${ }^{\mathrm{b}}$ The basin-wise population has been calculated from the "Gridded Population of the World adjusted to UN country level population estimates for 2010 and 2015" dataset produced by the Center for International Earth Science Information Network (CIESIN), Columbia University (http://sedac.ciesin.columbia.edu/data/collection/gpw-v4/ united-nations-adjusted)

\subsection{Key Issues of the HKH}

This assessment considers the key issues in the HKH region in the context of related questions that draws regional attention, cooperation and policy solutions. The HKH region is geologically fragile, with young and rising mountains, usually vulnerable to erosion and landslides, even without human interference. The region is undergoing rapid change driven by stressors such as climate change and human conflicts, and factors like globalization, infrastructure development, migration, tourism and urbanization. The outcome of interplay of these complex drivers of change is challenging to predict but will have major consequences, not just in the region but globally. There is a critical need to assess these drivers' potential cost to the HKH environment and human wellbeing as well as the opportunities they may present. Per capita fossil fuel $\mathrm{CO}_{2}$ emission from the $\mathrm{HKH}$ countries is one-sixth of the global average, however the region immensely suffers from the impact of climate change. Climate change is further enhanced by short-lived climate pollutants such as black carbon, which is emitted in large quantities in regions upwind of the HKH where dirty energy sources also have a large impact on health. From a policy standpoint, achieving food, water, energy, and livelihood security in the region will require exploring scenarios based on different assumptions so that the scientific community, policy-makers, the private sector, and community stakeholders can come together and make optimal governance decisions to sustain this global asset. It will also require country-specific recommendations to guide national-level policy-making.

\subsection{Overall Objective, Rationale and Key Questions}

\subsubsection{Overall Objective}

This assessment aims to (1) establish the global significance of the HKH, (2) reduce scientific uncertainty on various mountain issues, (3) lay out practical and up-to-date solutions and offer new insights for development of this region, (4) value and conserve existing ecosystems, cultures, societies, knowledge, and distinctive HKH solutions that are important to the rest of the world, (5) addresses contemporary policy questions, and (6) influence policy processes with robust evidence for sustainable mountain development.

\subsubsection{Rationale for the Assessment}

An assessment is distinct from a review. Whereas research speaks to other scientists in a particular field, assessments critically evaluate current states of knowledge about a topic with an aim to develop policy-oriented solutions, and inform relevant decision-makers across sectors. Assessments are structured to address specific social problems by translating science into forms that are salient, legitimate, and credible to wider audiences (Clark et al. 2006). Nevertheless, assessments also give due importance to reducing scientific uncertainty.

An integral part of assessments is indicating the level of confidence that chapter teams have concerning key findings, based on the available data, evidence and peer-reviewed publications. For the HIMAP Assessment it was decided to follow the four-box model adopted by the Intergovernmental Science-Policy Platform on Biodiversity and Ecosystem Services (IPBES) for the qualitative communication of confidence, which juxtaposes the level of agreement with the quantity and quality of the evidence. In the Chapter Overviews the following four confidence terms are used, in brackets and italics: (well established), (established but incomplete), (unresolved) and (inconclusive). For a key finding to be well established, the quantity and quality of the evidence is high as is the level of agreement. For inconclusive both are low, while for unresolved multiple independent studies exist but the conclusions do not agree (low level of agreement). Lastly, established but incomplete pertains to findings where the general level of agreement is high 
among experts, although only a limited number of studies exist and the level of evidence is low to moderate.

The target audiences for this assessment are those who make decisions on investments and management regarding mountain development, that is, policy-makers, government agencies, foundations, academics, natural resource managers, private-sector investors, and civil-society members. In addition, our assessment aims to inform the general public about important mountain issues so that everyone can help to make better decisions through political processes in HKH countries.

In 2007, the Intergovernmental Panel on Climate Change (IPCC's) fourth assessment report (Pachauri and Reisinger 2007) predicted that climate change will be the most prominent driver of global change in the 21 st century and pointed to the lack of consistent long-term monitoring in the HKH. The report called for national, regional, and global efforts to fill this data gap. Little progress was made in the HKH by the time of the IPCC's fifth assessment report (Pachauri and Meyer 2014). While universities, nongovernmental organizations, and scientific organizations have made strides in assembling and consolidating data, information on environment, natural resources and social systems of the HKH collectively remains too fragmented and incomplete to derive any meaningful conclusions about trends and scenarios.

The Hindu Kush Himalayan Monitoring and Assessment Programme (HIMAP), which brings together hundreds of scientists and experts from the region and around the world, aims to address these knowledge gaps and propose a way forward. This comprehensive assessment goes beyond climate change and is expected to greatly assist efforts to address threats and act on opportunities, and gives importance to upscale cutting-edge approaches. HIMAP derives inspiration from the Arctic Monitoring and Assessment Programme, which has systematically generated meaningful data and analysis about key trends and future scenarios on environment and natural resources in the Arctic region.

\subsubsection{Key Questions}

A set of questions relevant for the assessment was developed first by nalysing the key issues of the HKH region. The assessment was designed in a way that each chapter team considered relevant questions in writing their chapters. HIMAP has considered the following critical questions:

- What are the most important drivers of change in the $\mathrm{HKH}$, what is the role of climate change, and what are their potential impacts on biodiversity, ecosystem services, livelihoods, and water resources?

- What are the most important strategies, policies, and governance arrangements for enhancing community adaptation to drivers of change, including climate change; how can they be out-scaled; and what are their impacts?

- How do gender-equitable and inclusive approaches support sustainable mountain development, and how can these be realized?

- What migration trends exist in the region, what are their present impacts on livelihoods and the environment, how climate change is inducing migration and should migration be taken as adaptive strategy, and what are the options for addressing migration and the likely consequences of those options?

- What is the existing status of the cryosphere, what changes are likely, and what are the possible impacts of those changes?

- What is the current and likely future quantity, variability, and quality of the water in the 10 major river basins of the HKH; what are the potential impacts of change on water availability; and how can negative impacts be mitigated?

- What are the best means of reducing the risk of floods and droughts, and how can they be introduced at various scales, including on Transboundary Rivers?

- Why is air pollution increasing in the HKH, how is the HKH affected by air pollution from within and beyond the HKH, and how can the problem be reduced?

- What are the energy needs and possibilities for the people of the HKH, what are the positive and negative impacts of hydropower development, how effective and safe is hydropower generation as an economic enterprise, and how can hydropower best be sustainably developed in the region?

- How can ecosystems be managed to support soil and biodiversity conservation, and improved livelihoods in the various contexts found in the HKH?

- What ecosystem services do mountains provide, and how can management and supply of these services be compensated?

- What watershed-, landscape-, and forestry-based approaches will best support ecosystem services, food and water security, and community resilience?

- How can the HKH develop a green economy? What technologies (modern, traditional, and indigenous) and approaches are best suited for sustainable mountain development in the region, and how can they be outscaled?

\subsection{Vision}

The assessment foresaw the key issues of the region, drew 13 critical questions for addressing the identified issues, and both the issues and questions were used in formulating the 
vision of the assessment: To enable a prosperous, peaceful, and poverty-free people; food, energy, environment and water secure people; and climate- and disaster-resilient mountain communities for the region and the world.

(1) Prosperous - wellbeing in terms of productive and dignified, social (quality of life, social capital, healthy), cultural (identity plus integration), and environment (clean air, water, pollution management, and healthy natural resource base)

(2) Equality of access to opportunities and benefits of resources for everyone regardless gender and social class

(3) Food security - healthy people with access to adequate, affordable, good quality and nutritious food

(4) Energy security-access to adequate amount of energy that is affordable, non-polluting and sustainable, without unduly affecting the present low carbon status.

(5) Water security - access to quality, affordable water; and protection from extreme events such as floods and droughts

(6) Vibrant and bio-diverse ecosystem services for people to support culture and economies; protection and wise use of ecosystem services

(7) Climate and disaster resilient communities and countries; contributing to mitigation and adaptation; means-finance, capacity building, knowledge and technology

(8) Cooperation at all levels (people to people, business to business, government to government) between countries for sustainable and mutual benefits to achieve vision

(9) Unrestricted people movement across the $\mathrm{HKH}$ countries

(10) Recognition of the HKH region as a global asset.

\subsection{HKH Priorities Contributing to the Sustainable Development Goals}

Considering the issues, questions and vision as part of this assessment, we drafted our chapters and key messages in line with the United Nations' Sustainable Development Goals (SDGs). In this way, our "Priorities for Mountains and People of the HKH" reflect the ideals and inspiration of the SDGs. We created this complementarity through a three-step exercise:

(a) Define HKH priorities, align them with SDGs and refer to relevant HIMAP assessment chapters; (b) Define HKH specific targets for 2030 ;

(c) Identify suitable indicators derived from the list of proposed SDG indicators; and indicate data availability.

Table 1.3 lays out the relationship between $\mathrm{HKH}$ priorities and the SDG framework.

\subsection{Conceptual Framing of the Assessment}

The concept of the assessment was logically developed step by step by framing of key issues, identifying critical questions to address the issues and visioning of the exercise and identifying nine priorities that could contribute to 2030 SDGs.

Our assessment addresses the environmental, economic and social pillars of sustainable mountain development and will serve as a basis for evidence-based decision-making to safeguard the environment and advance people's wellbeing. This report will not be a one-time publication. It is planned as the first of a series of monitoring and assessment reports about the HKH.

In spite of the vast expanse of mountains and their importance in the world, as a unique and exclusive land form, they have been largely ignored within better known environmental assessments such as the IPCC and Millennium Ecosystem Assessment. In those assessments, mountains are not examined in detail: scientific knowledge is scattered and traditional indigenous knowledge systems are mostly absent. This assessment intends to fill these gaps and provide information for improved decision making in and for the HKH. HIMAP intends to provide a connection of this region in global assessments such as IPCC AR 6 and subsequent ones and IPBES, and intends to contribute to global targets like 2030 SDG goals, $1.5^{\circ}$ World after Paris UNFCCC 2015 agreement and Sendai Framework for Disaster Risk Reduction 2015.

The assessment chapters consider status, trends and scenarios on environmental, economic and social systems of the $\mathrm{HKH}$ region, and come up with recommendations that build into key policy messages. This assessment focuses on various drivers of change all of which are influenced by impacts of climate change. Mountain people and ecosystems tend to experience change more rapidly and with greater intensity. Mountain regions are no longer isolated from globalization. The HKH's biodiverse resources, rich indigenous knowledge systems, and enormous reservoirs of water provide vibrancy to the region and beyond. Understanding how these features may change over time is extremely important. In response, we devote many pages of this assessment to considering alternative development pathways and discussing ideas for enhancing regional cooperation in the $\mathrm{HKH}$ for sustainable mountain development. 


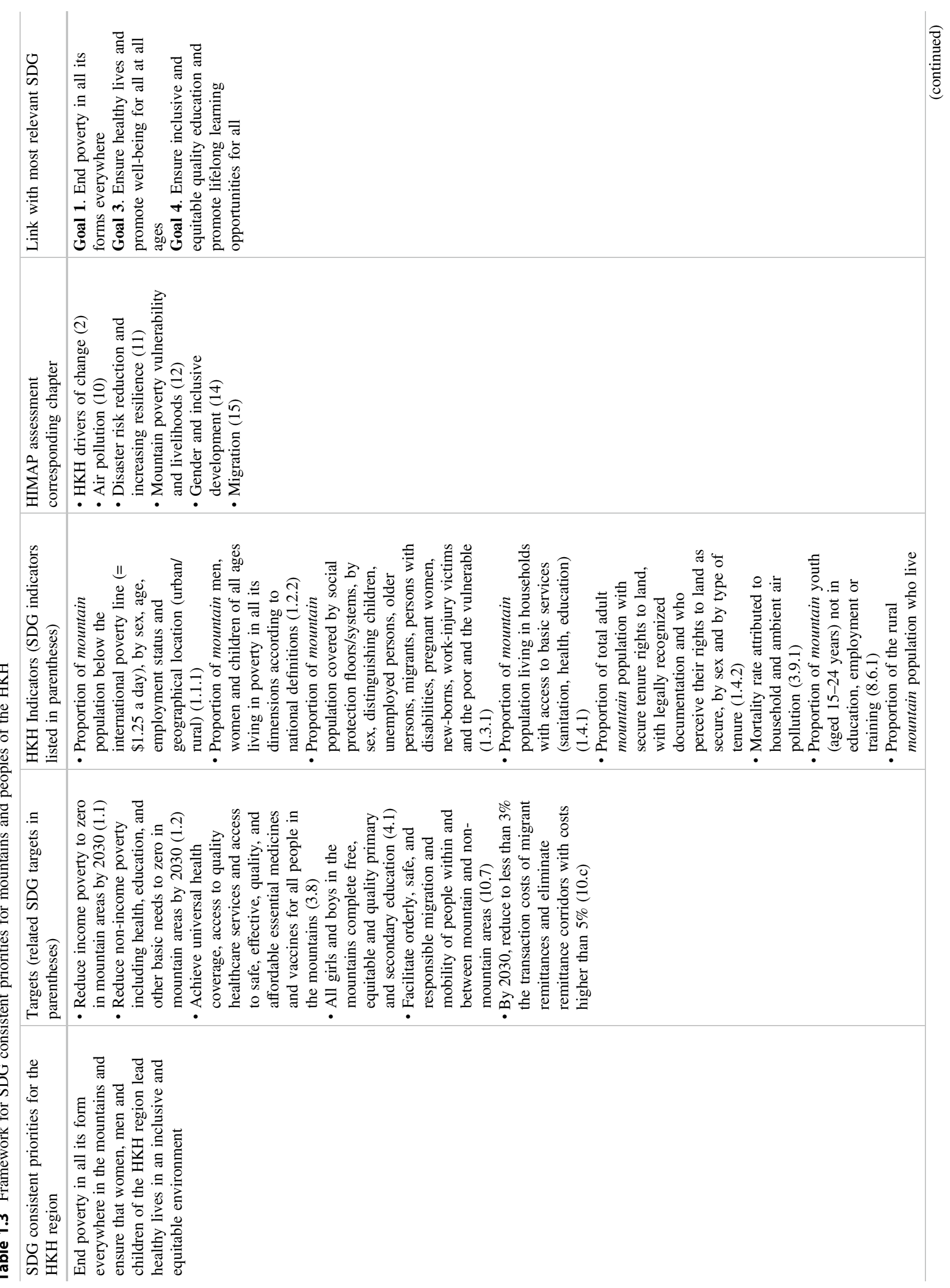




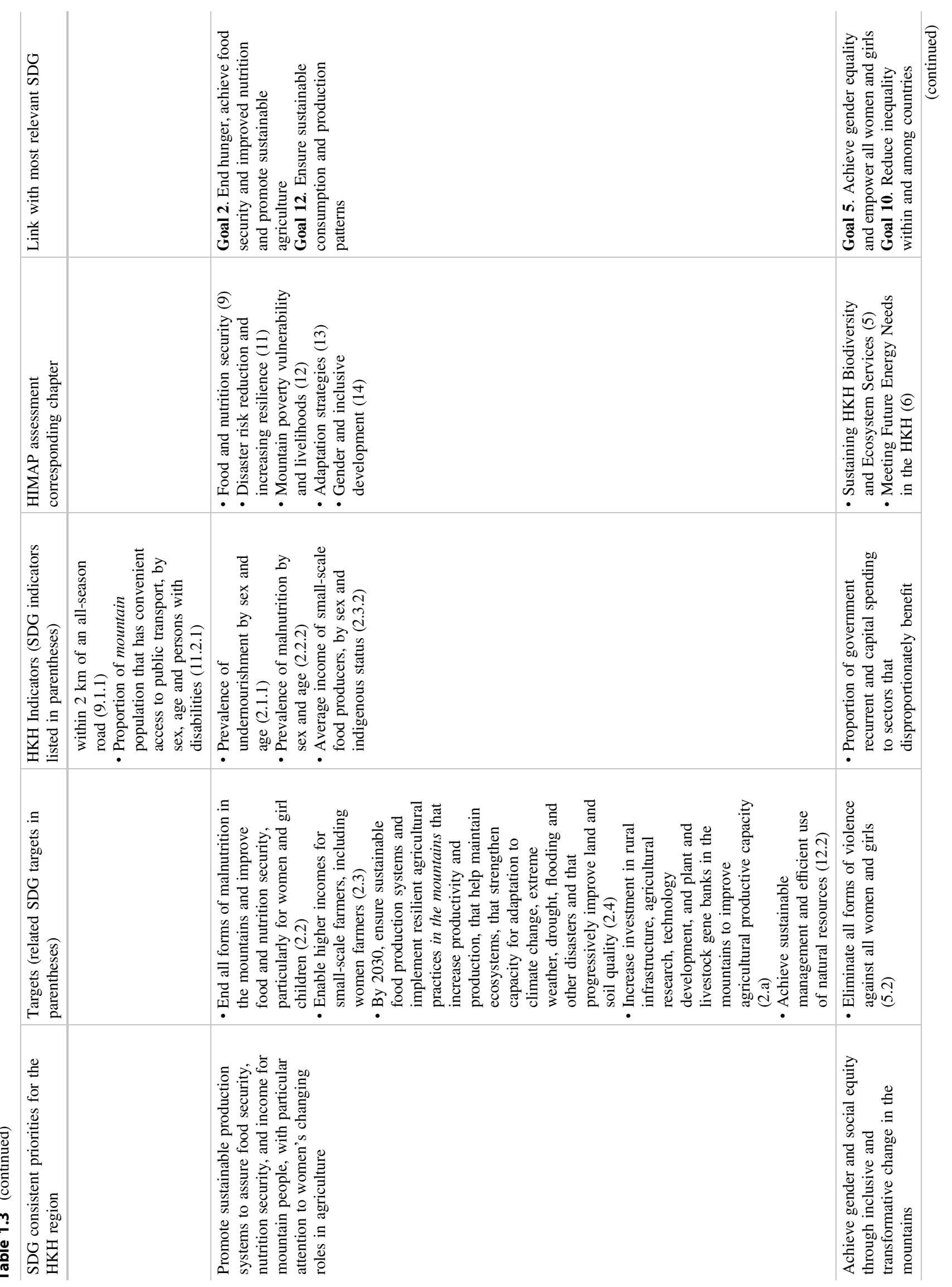




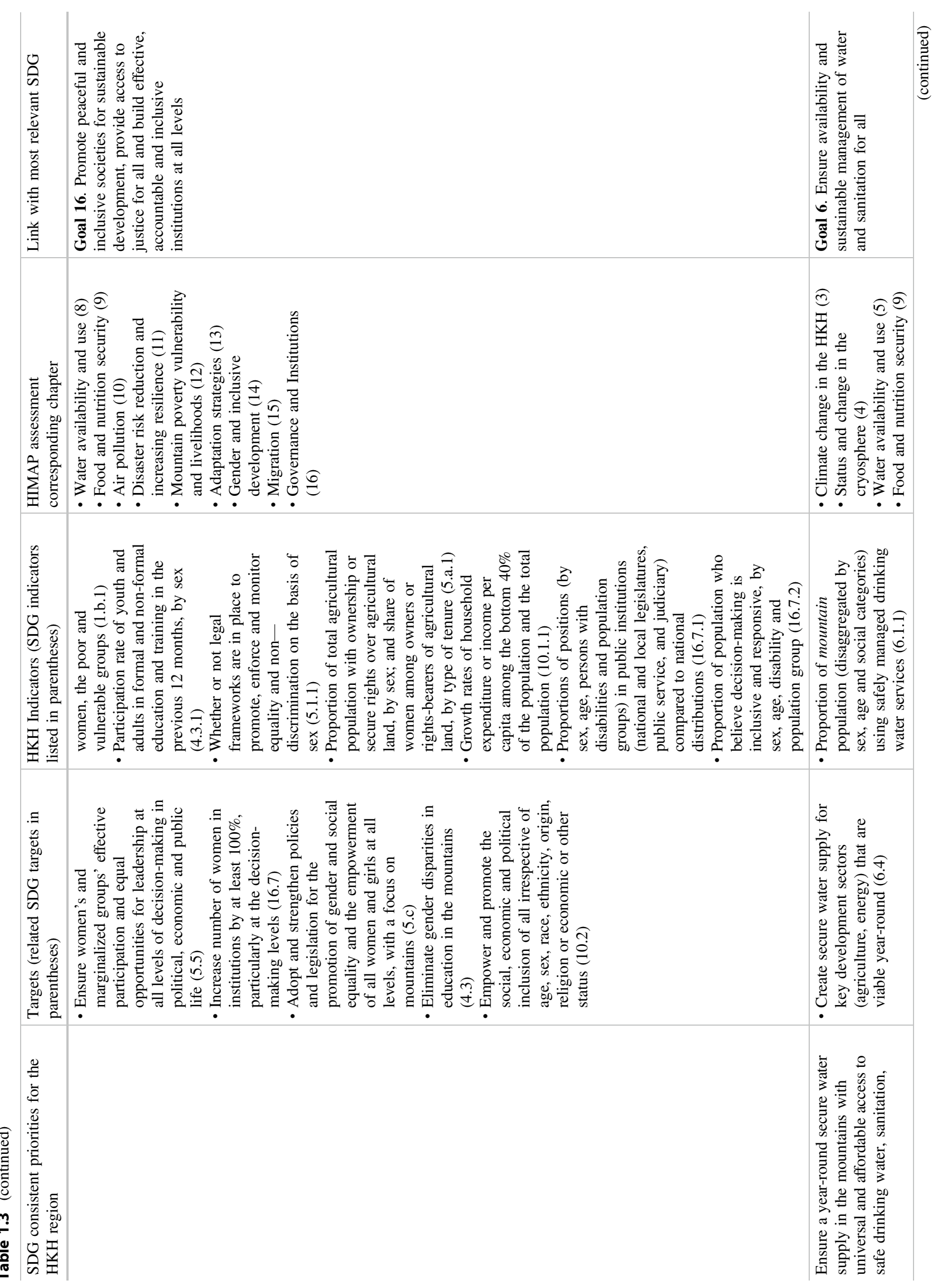




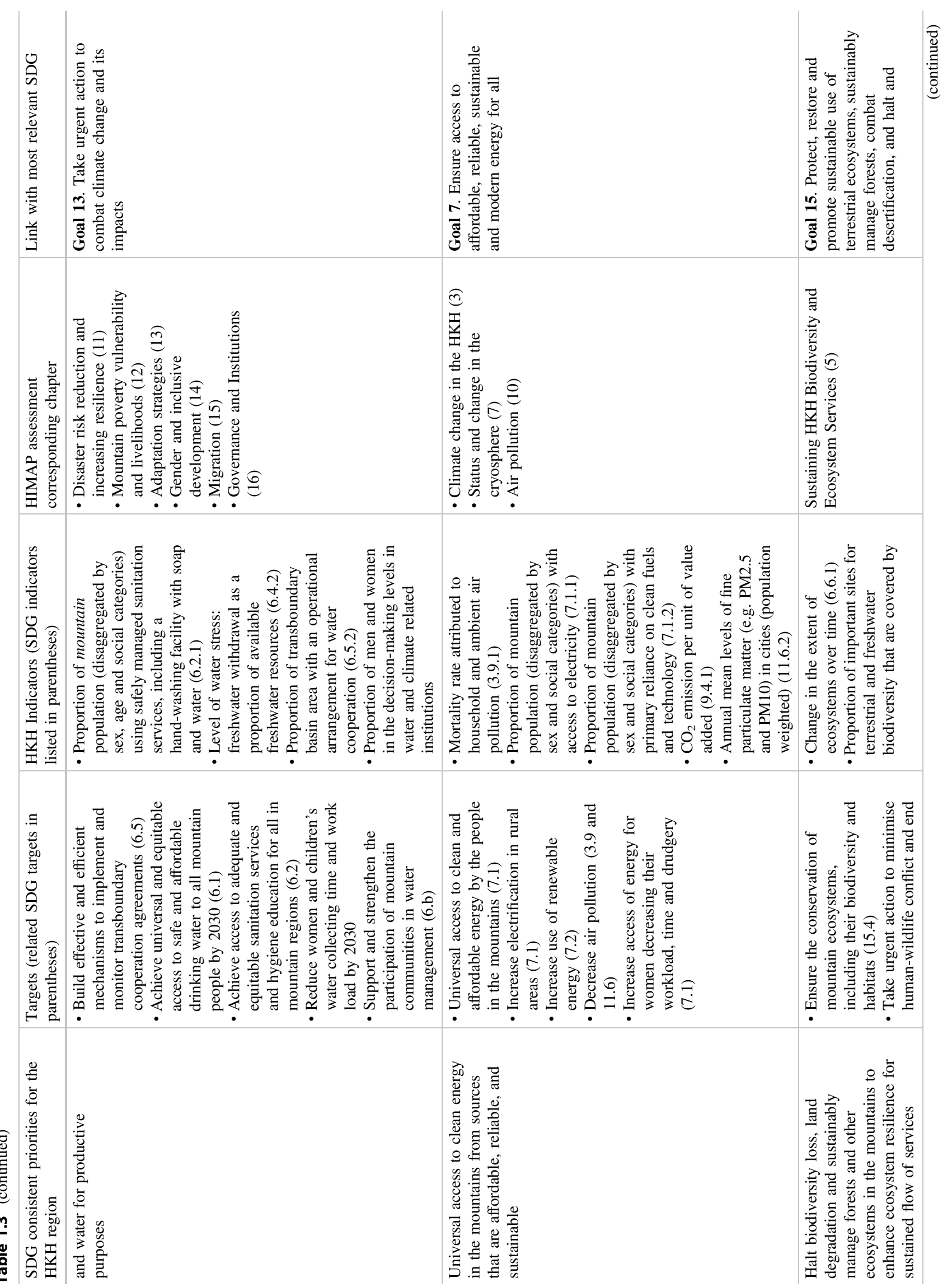




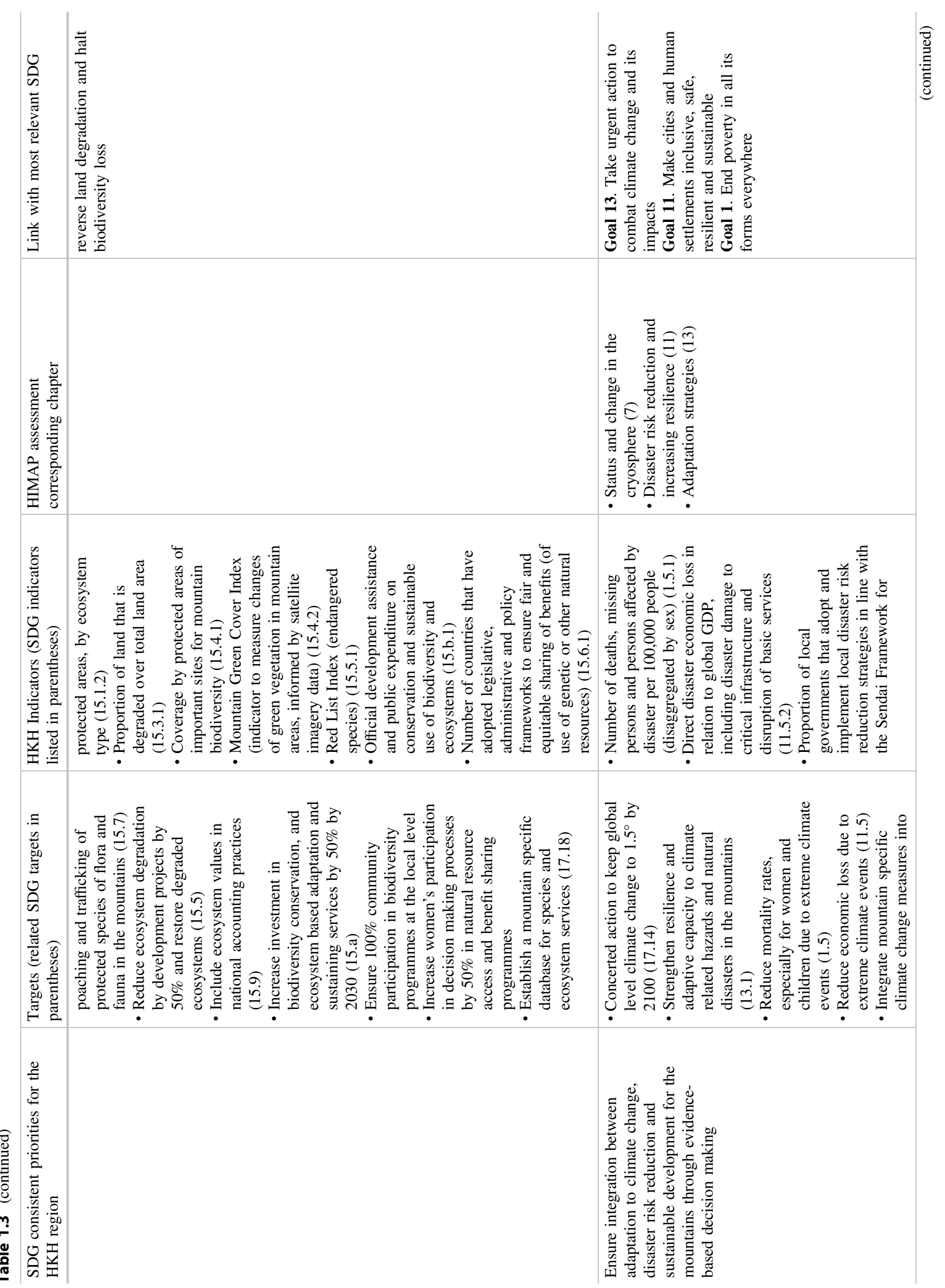




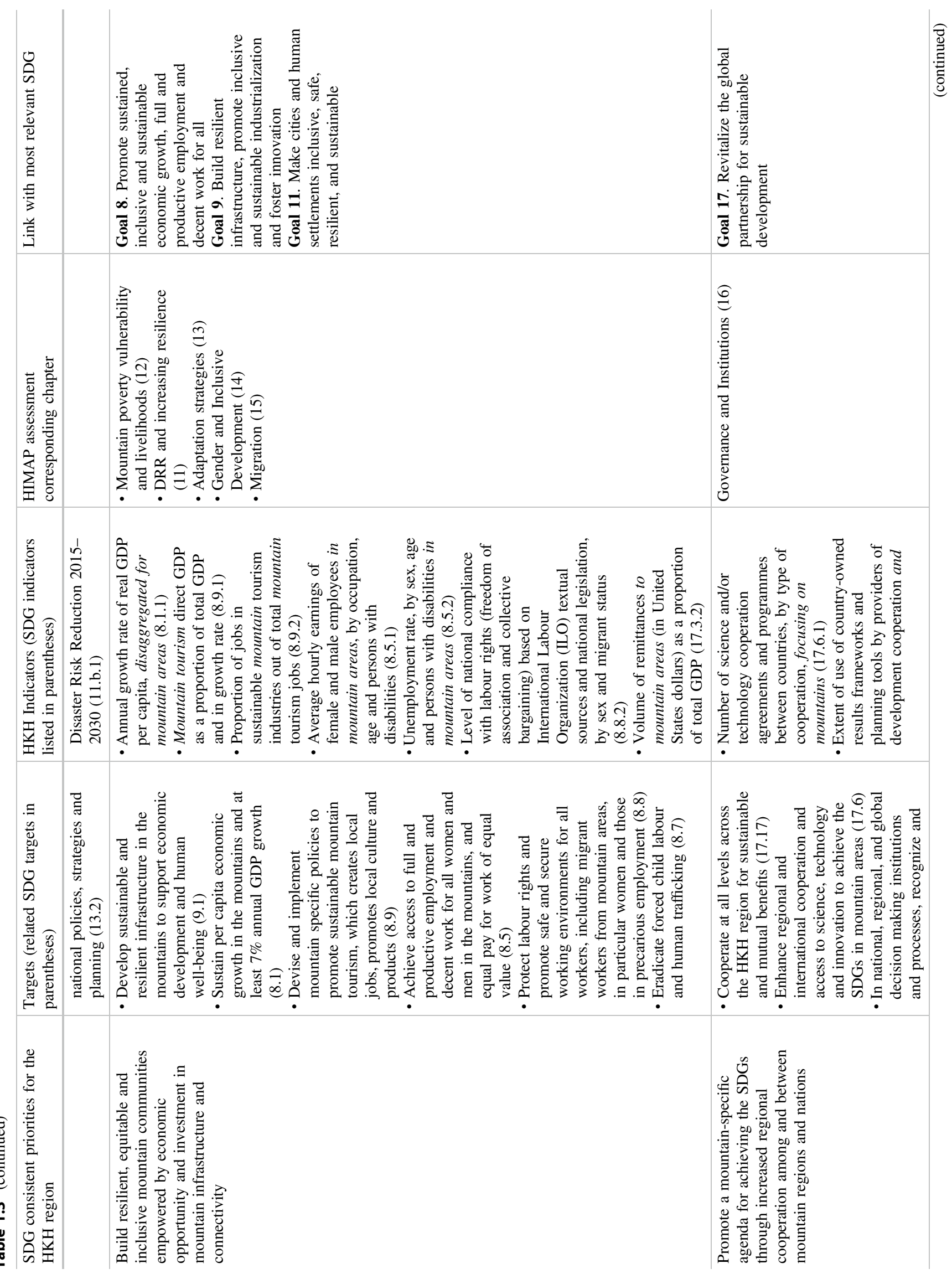




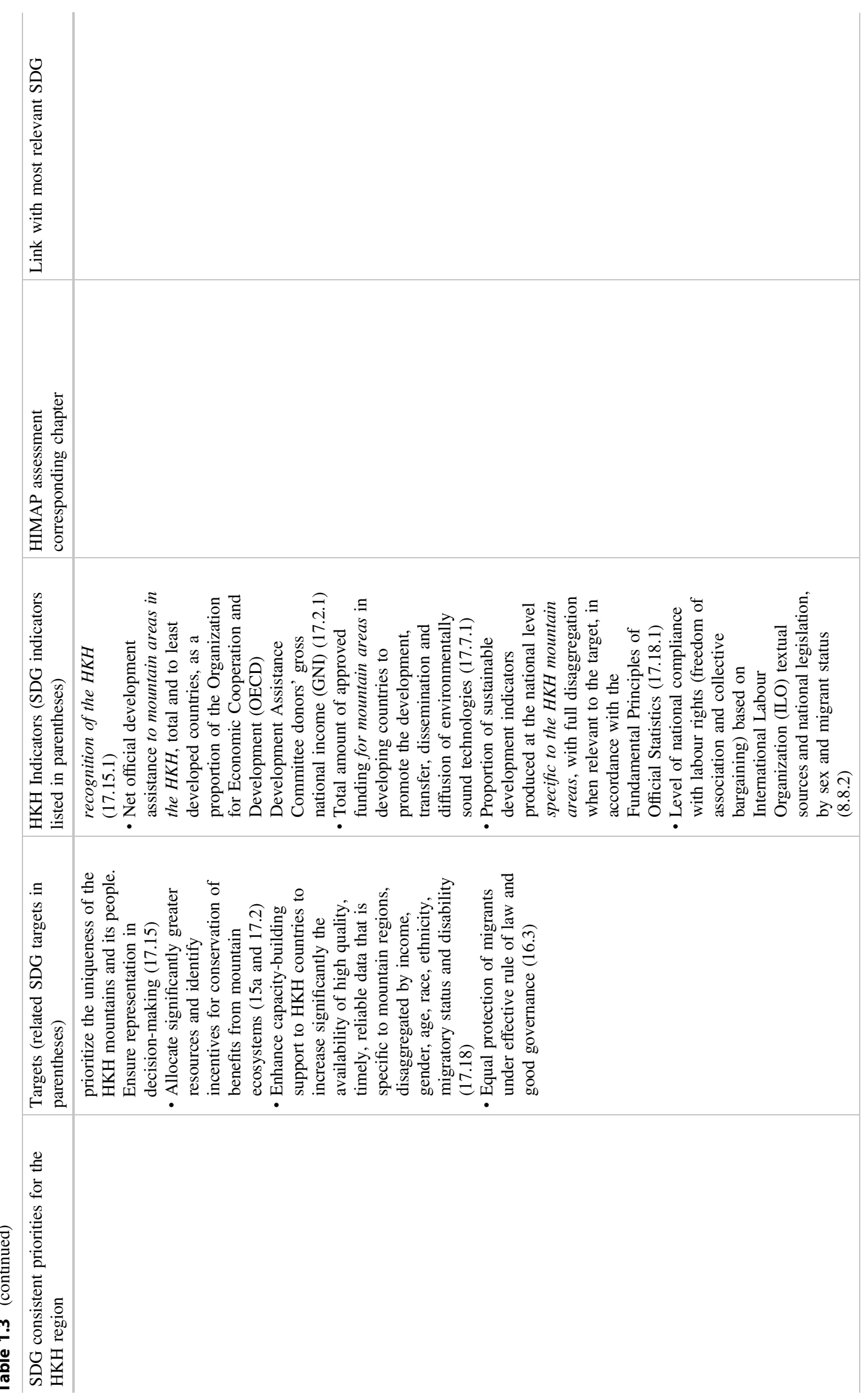




\subsection{Assessment Process}

The International Centre for Integrated Mountain Development (ICIMOD) coordinated HIMAP, constituted the chapter author teams and the process was steered by policy decisions of the Steering Committee. The assessment process involved several rounds of Steering Committee meetings, workshops of Coordinating Lead Authors and Lead Authors including write-shops and peer inter-chapter reviews, subject expert reviews, and open reviews for anyone interested. Science-policy dialogues were organized to develop key policy messages. For this assessment, HIMAP has engaged more than 300 researchers, practitioners, experts, and policy-makers. The publication of the first Comprehensive Assessment of the HKH in 2018 is planned as a wide-ranging, innovative evaluation of the current state of knowledge in the region and of various drivers of change and their impacts, and a set of practically oriented policy recommendations. The process is following these steps:

- Framing of the assessment: A framing workshop and consultations with various experts to define the structure and process of the assessment.

- Drafting of chapters: Based on the experience of other assessments, a network of people with in-depth knowledge of the region to draft the chapters.

- Peer review: Rigorously review the chapter drafts, both by peers and via open review.

- Dissemination: Using multiple channels, to communicate to a wide range of audiences during the process to draw attention while the assessment is still in preparation.

- Engagement with policy-makers: share with policymakers in the region through various processes.

- Development of a summary document: A summary for decision-makers based on the results of the process.

- Publication and launch: Publication of the first edition of the assessment in 2017.

\subsection{Outline of the Assessment}

Each chapter of the assessment address three broad themes within its particular confines:

(1) Defining the vision and state of knowledge;

(2) Drivers of change and integrated future scenarios; and

(3) Noting ideas and praxis for sustainable development.

The critical questions were used by each of the chapters to address the key issues of the region. The sixteen chapters include: Introduction — setting the scene: Drivers-local, regional, and global; Climate change in the HKH; Future scenarios; Sustaining HKH biodiversity and ecosystem services; Meeting future energy needs; The cryosphere; Water security -availability, use, and governance; Food and nutrition security; Air pollution; Disaster risk reduction and increasing resilience; Mountain poverty, vulnerability and livelihoods; Adaptation strategies; Gender and inclusive development; Migration; and Governance and institutions.

\section{References}

Bajracharya, S. R., \& Shrestha, B. (Eds.). (2011). The status of glaciers in the Hindu Kush-Himalayan region. Kathmandu: ICIMOD.

Bajracharya, S. R., Maharjan, S. B., Shrestha, F., Guo, W., Liu, S., Immerzeel, W., et al. (2015). The glaciers of the Hindu Kush Himalayas: Current status and observed changes from the 1980s to 2010. International Journal of Water Resources Development, 31 (2), 161-173.

Bangladesh Bureau of Statistics. (2001). Population and housing census 2001. Dhaka, Bangladesh: Statistics and Informatics Division, Ministry of Planning, Government of Bangladesh.

Bangladesh Bureau of Statistics. (2011). Population and housing census 2011. Dhaka, Bangladesh: Statistics and Informatics Division, Ministry of Planning, Government of Bangladesh.

Central Bureau of Statistics (2011). National population and housing census of Nepal (national report) 2011. Kathmandu, Nepal: National Planning Commission Secretariat, Government of Nepal. Retrieved from http://cbs.gov.np/image/data/Population/National\% 20Report/National\%20Report.pdf.

Central Statistics Organization. (2009). Statistical year book of Afghanistan 2008-09. Kabul, Afghanistan: Government of Islamic Republic of Afghanistan. Retrieved from http://cso.gov.af/Content/ files/Population\%20Full\%20chapter.pdf.

Central Statistics Organization (2017). Statistical year book of Afghanistan 2016-17. Kabul, Afghanistan: Government of Islamic Republic of Afghanistan. Retrieved from http://cso.gov.af/Content/ files/\%D8\%B3\%D8\%A7\%D9\%84\%D9\%86\%D8\%A7\%D9\%85\% D9\%87\%20\%D8\%A7\%D8\%AD\%D8\%B5\%D8\%A7\%D8\%A6\% $\mathrm{DB} \% 8 \mathrm{C} \% \mathrm{D} 9 \% 88 \% \mathrm{DB} \% 8 \mathrm{C} \% 20 \% \mathrm{D} 8 \% \mathrm{~B} 3 \% \mathrm{D} 8 \% \mathrm{~A} 7 \% \mathrm{D} 9 \% 84 \%$ 201395/Population.pdf.

Chettri, N., Shakya, B., Thapa, R., \& Sharma, E. (2008). Status of a protected area system in the Hindu Kush-Himalayas: An analysis of PA coverage. The International Journal of Biodiversity Science and Management, 4(3), 164-178.

Clark, W. C., Mitchell, R. B., \& Cash, D. W. (2006). Evaluating the influence of global environmental assessments. In R. B. Mitchell, W. C. Clark, D. W. Cash, \& N. M. Dickson (Eds.), Global environmental assessments: Information and influence (pp. 1-28). Cambridge, USA: MIT Press.

Dyurgerov, M. D., \& Meier, M. F. (2005). Glaciers and changing earth system: A 2004 snapshot. Boulder: Institute of Artic and Alpine Research, University of Colorado.

FAO. (2015). Mapping the vulnerability of mountain peoples to food insecurity. Rome, Italy: Food and Agriculture Organization of the United Nations.

Fleury, J. M. (1999). Mountain biodiversity at risk (Vol. 2, pp. 1-6). IDRC Briefing.

Gansu Provincial Bureau of Statistics. (2012). Statistical yearbook of Gansu Province 2012. Lanzhou, People's Republic of China: Government of Gansu Province. 
Gansu Provincial Bureau of Statistics. (2016). Statistical yearbook of Gansu Province 2016. Lanzhou, People's Republic of China: Government of Gansu Province.

Hamilton, L. S. (2002). Why mountain matters? World Conservation: The IUCN Bulletin 1/2002.

Kapos, V., Rhind, J., Edwards, M., Price, M. F., \& Ravilious, C. (2000). Developing a map of the world's mountain forests. In M. F. Price \& N. Butt (Eds.), Forests in Sustainable Mountain Development: A State-of-Knowledge Report for 2000 (pp. 4-9). Wallingford: $\mathrm{CAB}$ International.

Ministry of Home Affairs. (2001). Population census 2001. Delhi, India: Office of the Registrar General and Census Commissioner, Ministry of Home Affairs, Government of India. Retrieved from http://www.censusindia.gov.in/2011-common/census_data_2001. html.

Ministry of Home Affairs. (2011). Population census 2011. Delhi, India: Office of the Registrar General and Census Commissioner, Ministry of Home Affairs, Government of India. Retrieved from http://www.censusindia.gov.in/2011-common/census_data_2001. html.

Molden, D., \& Sharma, E. (2013). ICIMOD's strategy for delivering high-quality research and achieving impact for sustainable mountain development. Mountain Research and Development, 33(2), 179183.

National Bureau of Statistics of China. (2012). Statistical yearbook of China 2012. Beijing, China: Government of the People's Republic of China. Retrieved from http://www.stats.gov.cn/tjsj/ndsj/2012/ indexeh.htm.

National Bureau of Statistics of China. (2016). Statistical yearbook of China 2016. Beijing, China: Government of the People's Republic of China. Retrieved from http://www.stats.gov.cn/tjsj/ndsj/2016/ indexeh.htm.

National Statistics Bureau. (2016). Statistical year book of Bhutan 2016. Thimphu, Bhutan: Government of Bhutan. Retrieved from http://www.nsb.gov.bt/publication/files/SYB_2016.pdf.

Nogues-Bravo, D., Araujo, M. B., Romdal, T., \& Rahbek, C. (2008). Scale effects and human impact on the elevational species richness gradients. Nature, 453(8), 216-220.

Pachauri, R. K., \& Reisinger, A. (Eds.). (2007). In Climate change 2007: Synthesis report. Contribution of working groups I, II and III to the fourth assessment report of the intergovernmental panel on climate change. Geneva, Switzerland: Intergovernmental Panel on Climate Change. Retrieved March 12, 2016, from www.ipcc.ch/ report/ar4/.

Pachauri, R. K., \& Meyer, L. A. (Eds.). (2014). Climate change 2014: Synthesis Report. Contribution of working groups I, II and III to the fifth assessment report of the intergovernmental panel on climate change. Geneva, Switzerland: Intergovernmental Panel on Climate Change. Retrieved March 12, 2016, from www.ipcc.ch/report/ar5/.
Pakistan Bureau of Statistics. (1998). Population census 1998. Islamabad: Government of Pakistan. Retrieved from http://www. pbs.gov.pk/content/population-census.

Pakistan Bureau of Statistics. (2017). Population census 2017. Islamabad: Government of Pakistan. Retrieved from http://www. pbs.gov.pk/content/population-census.

Planning and Development Department. (2014). Azad Jammu and Kashmir at a Glance 2014 (report). The government of Pakistan. Retrieved from https://pndajk.gov.pk/uploadfiles/downloads/AJK\% 20at\%20a\%20glance\%202014.pdf.

Planning and Development Department. (2013). Gilgit-Baltistan Azad Jammu and Kashmir at a Glance 2013. Muzaffarabad, Pakistan: Statistical Cell, Planning and Development Department, Government of Gilgit-Baltistan. Retrieved from http://www.gilgitbaltistan. gov.pk/DownloadFiles/GBFinancilCurve.pdf.

Schild, A., \& Sharma, E. (2011). Sustainable mountain development revisited. Mountain Research and Development, 31(3), 237-241.

Sichuan Provincial Bureau of Statistics. (2012). Statistical yearbook of Sichuan Province 2012. Chengdu, People's Republic of China: Government of Sichuan Province.

Sichuan Provincial Bureau of Statistics. (2016). Statistical yearbook of Sichuan Province 2016. Chengdu, People's Republic of China: Government of Sichuan Province.

The Ministry of Immigration and Population. (2014). Population and housing census of Myanmar 2014 (State wise reports). Nay Pyi Taw, Myanmar: Department of Population, Ministry of Immigration and Population, Government of Myanmar.

UNEP-WCMC. (2002). Mountain watch: Environmental change and sustainable development in mountains. Cambridge, UK: UNEPWorld Conservation Monitoring Centre.

Whiteman, D. (2000). Mountain meteorology. London: Oxford University Press.

Xinjiang Autonomous Region Bureau of Statistics. (2012). Statistical yearbook of Xinjiang autonomous region 2012. Ürümqi, People's Republic of China: Government of Xinjiang Autonomous Region.

Xinjiang Autonomous Region Bureau of Statistics. (2016). Statistical yearbook of Xinjiang autonomous region 2016. Ürümqi, People's Republic of China: Government of Xinjiang Autonomous Region.

Xu, J., \& Melick, D. (2006). Emancipating indigenous knowledge: Can traditional cultures assist Himalayan sustainable development. Sustainable Mountain Development, 50, 31-35.

Yunnan Provincial Bureau of Statistics. (2012). Statistical yearbook of Yunnan Province 2012. Kunming, People's Republic of China: Government of Yunnan Province.

Yunnan Provincial Bureau of Statistics. (2016). Statistical yearbook of Yunnan Province 2016. Kunming, People's Republic of China: Government of Yunnan Province.
Open Access This chapter is licensed under the terms of the Creative Commons Attribution 4.0 International License (http:/l creativecommons.org/licenses/by/4.0/), which permits use, sharing, adaptation, distribution and reproduction in any medium or format, as long as you give appropriate credit to the original author(s) and the source, provide a link to the Creative Commons license and indicate if changes were made.
The images or other third party material in this chapter are included in the chapter's Creative Commons license, unless indicated otherwise in a credit line to the material. If material is not included in the chapter's Creative Commons license and your intended use is not permitted by statutory regulation or exceeds the permitted use, you will need to obtain permission directly from the copyright holder. 